ISSN: $1410-8917$

Jurnal Kimia

Sains \&

Aplikasi
Jurnal Kimia Sains dan Aplikasi Journal of Scientific and Applied Chemistry

Journal homepage: http://ejournal.undip.ac.id/index.php/ksa



\title{
Studi Pengaruh Temperatur terhadap Pengendapan Kobalt (Co) dengan Keberadaan Logam Seng (Zn) dalam Media Sulfat
}

\author{
Sonita Afrita Purba ${ }^{a}$, Linda Suyati ${ }^{\mathrm{a}^{*}}$, Didik Setiyo Widodo ${ }^{\mathrm{a}}$ \\ a Chemistry Department, Faculty of Sciences and Mathematics, Diponegoro University, Jalan Prof. Soedarto, Tembalang, Semarang \\ * Corresponding author: linda.suyati@live.undip.ac.id
}

Article Info

Keywords:

Electrolysis, cobalt, zinc

Kata Kunci:

Elektrolisis, kobalt, seng

\begin{abstract}
Research on the effect of temperature on cobalt (Co) deposition in the presence of zinc impurities $(\mathrm{Zn})$ in sulphate media has been done. The objective of this study was to determine the composition of Co and $\mathrm{Zn}$ precipitates in the variation of deposition temperature and determine the best temperature in cobalt deposition in the presence of impurities. The method used is electrolysis with fixed installed potential and temperature variation. Research stages include preparation of the solution, determination of decomposition potential, sample electrolysis under various conditions and analysis. The result of decomposition potential determination was used as the potential application price at cobalt electrolysis process that was $3.5 \mathrm{~V}$. The sample electrolysis was carried out at a potential of $3.5 \mathrm{~V}, \mathrm{pH}$ of a 3.0 solution in $100 \mathrm{~mL}$ volume at each temperature of $30,40,50,60,70$ and $80^{\circ} \mathrm{C}$. The precipitates obtained were analyzed using Scanning Electron Microscopy (SEM) and Energy Dispersive X-Ray Spectroscopy (EDS). The result of SEM analysis showed that the best morphology was possessed by sediment temperature $60^{\circ} \mathrm{C}$ with fine grain surface and the smallest diameter is $0.26 \mu \mathrm{m}$. The EDS analysis results also show that the best results are owned by the electrolysis temperature of $60^{\circ} \mathrm{C}$ with Co composition of $99.73 \%$ and containing $0.27 \% \mathrm{Zn}$.
\end{abstract}

\section{Abstrak}

Penelitian tentang pengaruh temperatur terhadap pengendapan kobalt (Co) dengan keberadaan pengotor seng $(\mathrm{Zn})$ dalam media sulfat telah dilakukan. Tujuan penelitian ini adalah untuk menentukan komposisi endapan Co dan Zn pada variasi temperatur pengendapan serta menentukan temperatur terbaik dalam pengendapan kobalt dengan adanya logam pengotor. Metode yang digunakan adalah elektrolisis dengan potensial terpasang tetap dan variasi temperatur. Tahapan penelitian meliputi preparasi larutan, penentuan potensial dekomposisi, elektrolisis sampel pada berbagai kondisi dan analisis. Hasil penentuan potensial dekomposisi digunakan sebagai harga potensial aplikasi pada proses elektrolisis kobalt yaitu sebesar 3,5 V. Elektrolisis sampel dilakukan pada potensial $3,5 \mathrm{~V}$, pH larutan 3,0 dalam volume $100 \mathrm{~mL}$ pada masing-masing temperatur $30,40,50,60,70$ dan $80^{\circ} \mathrm{C}$. Endapan yang diperoleh dianalisis dengan menggunakan Scanning Electron Microscopy (SEM) dan Energy Dispersive X-Ray Spectroscopy (EDS). Hasil analisis SEM menunjukkan bahwa morfologi terbaik dimiliki oleh endapan suhu $60^{\circ} \mathrm{C}$ dengan permukaan butiran halus dan diameter terkecil yaitu sebesar 0,26 $\mu \mathrm{m}$. Hasil analisis EDS juga menunjukkan bahwa hasil terbaik dimiliki oleh deposit hasil elektrolisis suhu $60^{\circ} \mathrm{C}$ dengan komposisi Co sebesar 99,73\% dan mengandung $0,27 \% \mathrm{Zn}$. 


\section{Pendahuluan}

Kobalt merupakan logam yang terkandung pada lapisan bumi dengan jumlah yang kecil. Hanya ada sekitar 20 ppm kobalt di kerak bumi tetapi sangat dibutuhkan dalam kehidupan manusia sebagai komponen utama vitamin $\mathrm{B}_{12}$ yang membantu proses pembaharuan sel darah merah. Metode yang digunakan untuk memperoleh kembali logam kobalt dari alam yaitu metode elektrolisis logam dari larutan yang disebut sebagai proses elektrowinning.

Logam yang sering dikaji dalam proses elektrowinning selain kobalt adalah logam seperti $\mathrm{Sb}$, $\mathrm{Ni}, \mathrm{Cu}, \mathrm{Fe}, \mathrm{As}$, dan $\mathrm{Zn}$ [1]. Elektrowinning dipengaruhi oleh beberapa aspek seperti overvoltage, kerapatan arus, efisiensi arus, dan kualitas logam yang dimurnikan. Pengukuran overvoltage oleh $\mathrm{Yu}, 2010$ menunjukkan bahwa dengan penambahan konsentrasi Co dalam larutan pada proses elektrolisis menyebabkan potensial reduksi menurun dan kerapatan arus meningkat sedangkan Nguyen, 2008 mengungkapkan bahwa perubahan potensial elektroda saat reduksi tembaga menurun ketika konsentrasi $\mathrm{Co}^{2+}$ ditingkatkan dan konsentrasi asam sebagai elektrolit diturunkan. Kongolo $d k k$. [2] juga melakukan penelitian tentang kontribusi deposisi Ni dan Zn terhadap elektrowinning Co, hasil menunjukkan bahwa meningkatnya konsentrasi Co mempengaruhi penurunan pengendapan logam Ni dan Zn. Dalam proses elektrowinning kobalt (Co) terdapat parameter yang mempengaruhi pengendapan yaitu temperatur, $\mathrm{pH}$ larutan dan kerapatan arus. Kondisi optimum pengendapan dengan suhu $60^{\circ} \mathrm{C}$, range $\mathrm{pH}$ larutan sebesar 3,0-4,0 dan rapat arus sebesar 400 $\mathrm{A} / \mathrm{m}^{2}$. Kobalt diendapkan dalam media sulfat dengan perubahan temperatur, $\mathrm{pH}$ dan arus namun belum mempertimbangkan adanya pengaruh logam pengotor dalam sistem seperti yang telah dilakukan [2].

Pengaruh logam pengotor dan kondisi optimum pengendapan perlu diperhatikan untuk memperoleh endapan yang terbaik. Endapan yang baik haruslah berbulir halus, seragam dan nampak seperti logam. Endapan dengan tampilan morfologi berongga, serbuk maupun gumpalan memiliki kemurnian yang kurang baik dan tidak melekat dengan baik di elektroda. Faktor utama yang mempengaruhi sifat fisik pengendapan adalah temperatur [3], sehingga perlu dikaji pengaruhnya terhadap pengendapan kobalt (Co). Pada penelitian ini akan dikaji proses elektrolisis kobalt pada perubahan temperatur dengan tidak hanya mempertimbangkan $\mathrm{pH}$ sebagai kondisi optimum tetapi juga mempertimbangkan adanya logam pengganggu dalam sitem elektrolisis [2].

\section{Metode Penelitian}

Alat dan Bahan

Alat-alat gelas, timbangan listrik, multimeter, penghitung waktu, elektroanalizer GW INSTEK GPA30600 dan $\mathrm{pH}$ meter Schoott. Akuades, $\mathrm{CoSo}_{4} \cdot 7 \mathrm{H}_{2} \mathrm{O}$, $\mathrm{ZnSO}_{4.7} 7 \mathrm{H}_{2} \mathrm{O}$. dan $\mathrm{H}_{2} \mathrm{SO}_{4} 96 \%$.

\section{Prosedur Penelitian}

Sampel yang digunakan merupakan sampel percontohan. Sampel dibuat dengan pencampuran $\mathrm{CoSO}_{4}$ 0,1 $\mathrm{M}$ dengan akuades dan pencampuran $\mathrm{ZnSO}_{4}$ $100 \mathrm{mgL}-1$ dengan akuades. Elektrolit yang digunakan adalah $\mathrm{H}_{2} \mathrm{SO}_{4} \quad 96 \%$ dengan pengkondisian sampel larutan $\mathrm{pH}$ 3,0. Pengukuran potensial deposisi dilakukan pada larutan $\mathrm{Co}^{2+}$ 0,05 $\mathrm{M}$ dengan dan tanpa pengotor $\mathrm{Zn}^{2+} 100 \mathrm{mgL}^{-1}$ serta sistem pelarut. Seluruh sampel dikondisikan pada $\mathrm{pH} 3$ dengan penambahan $\mathrm{H}_{2} \mathrm{SO}_{4} 96 \%$ pada gelas beker $100 \mathrm{~mL}$. Penentuan potensial deposisi kobalt dengan mengkondisikan Temperatur $298 \mathrm{~K}$, potensial diatur dari 1,0 hingga 10,0 V serta dilakukan pengukuran arus terbaca. Data yang diperoleh kemudian diplotkan pada kurva hubungan antara potensial (E) terhadap arus (I) sehingga dapat ditentukan nilai potensial deposisi dari kobalt. Sebanyak $50 \mathrm{ml}$ larutan $\mathrm{Co}^{2+}$ 0,1 $\mathrm{M}$ dan $100 \mathrm{mgL}^{-1} \mathrm{Zn}^{2+}$ serta elektrolit pendukung berupa $\mathrm{H}_{2} \mathrm{SO}_{4} 96 \%$ pada gelas beker $100 \mathrm{ml}$. Dilakukan elektrolisis selama 6 jam dengan temperatur 30, 40, 50, 60,70 dan $80^{\circ} \mathrm{C}$. Penentuan potensial aplikasi dilakukan pada larutan $\mathrm{Co}^{2+}$ dengan dan tanpa $\mathrm{Zn}^{2+}$ serta sistem pelarut yang menghasilkan grafik ektrapolasi masingmasing larutan yang selanjutnya disebut potensial dekomposisi. Hasil deposit yang diperoleh pada pengendapan dengan potensial aplikasi terpasang kemudian ditentukan massa, bulir kristal dan komposisi deposit, massa dan kemurnian kobalt, serta efisiensi arus. Analisis dengan menggunakan SEM-EDS dapat menentukan komposisi dan morfologi deposit yang terendapkan, massa kobalt dan seng yang terendapkan serta kemurnian kobalt dengan keberadaan logam seng.

\section{Hasil dan Pembahasan}

\section{Penentuan Potensial Dekomposisi Kobalt (Co)}

Penentuan potensial dekomposisi dilakukan terhadap larutan $\mathrm{CoSO}_{4}$, larutan $\mathrm{CoSO}_{4}$ dengan keberadaan $\mathrm{ZnSO}_{4}$, serta sistem pelarut yang bertujuan agar harga potensial dekomposisi yang diperoleh sesuai dengan kondisi sampel yang akan dielektrolisis yaitu mengandung pengotor seng ( $\mathrm{Zn}$ ). Proses ini dilakukan dengan mengelektrolisis larutan pada variasi potensial mulai dari 1,0 - $10 \mathrm{~V}$ dengan interval 1,0 V setiap 2 menit dan pembacaan arus pada tiap-tiap tahap. Arus yang dicatat selanjutnya dialurkan dalam suatu grafik hubungan antara potensial dan arus masing-masing larutan sampel dan sistem pelarut. Larutan yang digunakan dalam proses ini terdiri atas $\mathrm{Co}^{2+}$ 0,05 $\mathrm{M}$ dengan dan tanpa $\mathrm{Zn}^{2+} 100 \mathrm{mgL}^{-1}$ dan akuades sebagai sistem pelarut. Masing-masing larutan sampel dikondisikan pada $\mathrm{pH} 3$ dengan penambahan $\mathrm{H}_{2} \mathrm{SO}_{4}$ $96 \%$. Penentuan potensial dekomposisi larutan $\mathrm{Co}^{2+}$ dengan dan tanpa $\mathrm{Zn}^{2+}$ serta sistem pealrut ditunjukkan oleh Gambar 1. 


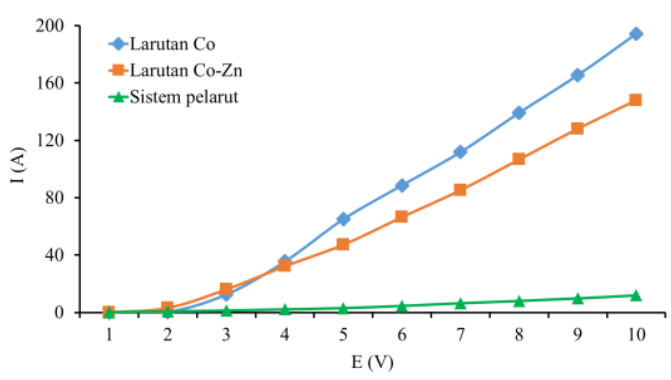

Gambar 1. Potensial dekomposisi larutan $\mathrm{Co}^{2+}$ dengan dan tanpa $\mathrm{Zn}^{2+}$ serta sistem pelarut

Hubungan antara potensial yang diberikan pada larutan $\mathrm{Co}^{2+}$ dengan arus listrik yang mengalir di dalam sistem tersebut. Potensial dekomposisi $\mathrm{Co}^{2+}$ tanpa keberadaan $\mathrm{Zn}^{2+}$ adalah sebesar $2,60 \mathrm{~V}, \mathrm{Co}^{2+}$ dengan keberadaan $\mathrm{Zn}^{2+}$ sebesar $2,63 \mathrm{~V}$ serta sistem pelarut sebesar 5,0 V, sehingga ditetapkan potensial aplikasi sebesar 3,5 V sebagai harga potensial tetap dalam sitem elektrolisis.

Pengaruh Keberadaan Seng (Zn) dan Kenaikan Temperatur pada Elektrolisis Kobalt

Elektrolisis masing-masing sampel larutan $\mathrm{pH} 3$ dilakukan dengan perubahan temperatur mulai dari 30 , $40,50,60,70$, hingga $80^{\circ} \mathrm{C}$ dengan potensial terpasang sebesar 3,5 V selama 6 jam. Hasil elektrolisis kobalt pada masing-masing temperatur dapat ditunjukkan pada Tabel 1.

Tabel 1: Data berat kobalt pada elektrolisis berbagai temperatur

\begin{tabular}{cc}
\hline Temperatur $\left({ }^{\circ} \mathrm{C}\right)$ & Massa deposit $(\mathrm{g})$ \\
\hline 30 & 0,0586 \\
40 & 0,0629 \\
50 & 0,0699 \\
60 & 0,0806 \\
70 & 0,0718 \\
80 & 0,0513 \\
\hline
\end{tabular}

Hasil analisis EDS pada endapan hasil elektrolisis pada berbagai temperatur ditunjukkan oleh gambar 2-5.

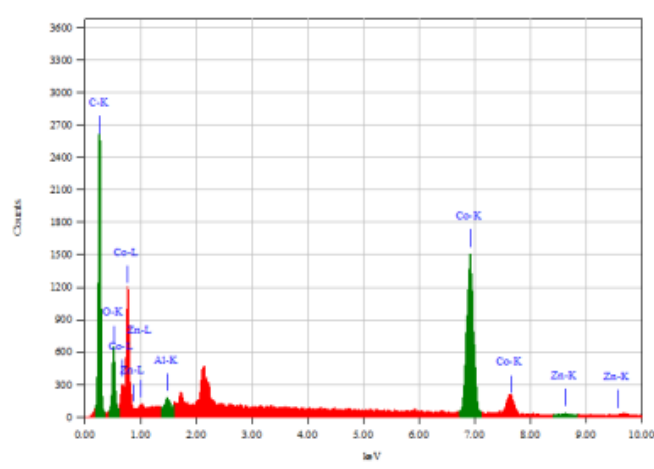

Gambar 2. Komposisi unsur endapan pada elektrolisis suhu $50^{\circ} \mathrm{C}$

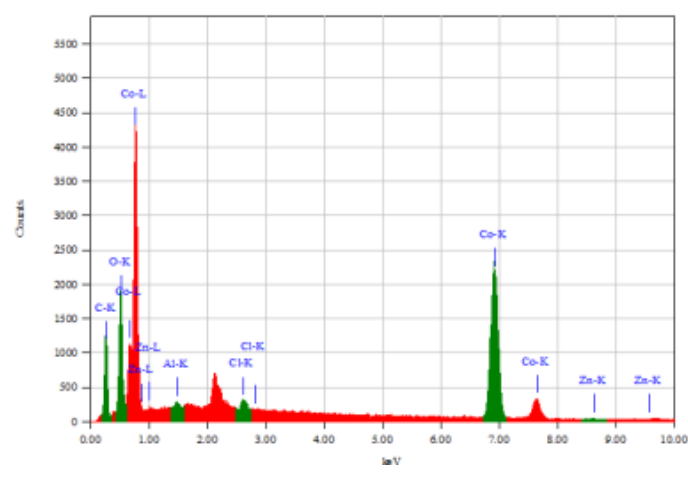

Gambar 3. Komposisi unsur endapan pada elektrolisis suhu $60^{\circ} \mathrm{C}$

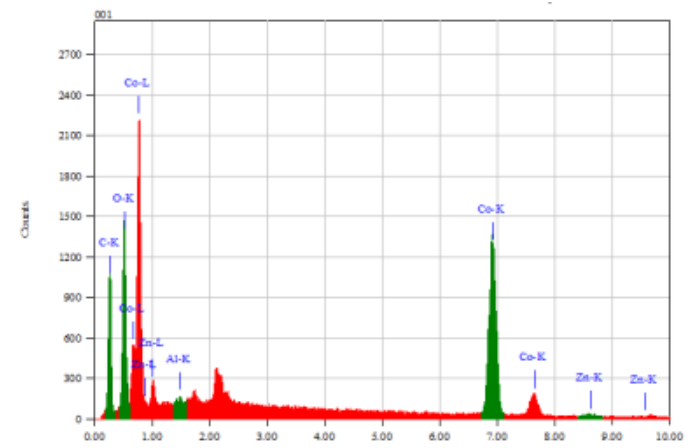

Gambar 4. Komposisi unsur endapan pada elektrolisis suhu $70^{\circ} \mathrm{C}$

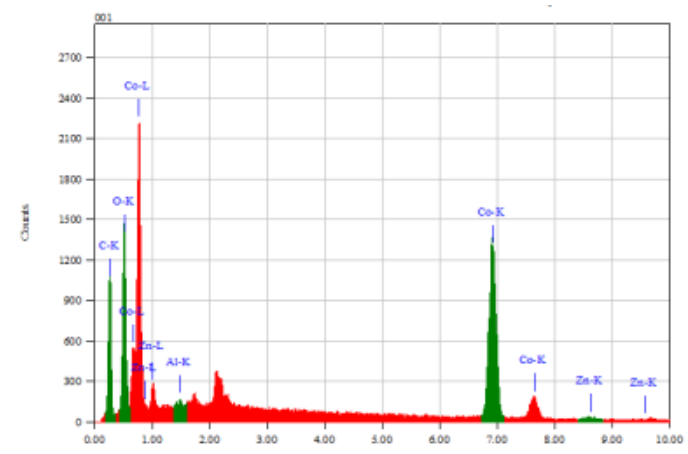

Gambar 5. Komposisi unsur endapan pada elektrolisis suhu $80^{\circ} \mathrm{C}$

Komposisi Co pada endapan hasil elektrolisis pada berbagai suhu 50, 60, 70 dan $80^{\circ} \mathrm{C}$ masing-masing sebesar 98,44\%; 99,73\%; 98,98\% dan 98,10\%. Sedangkan komposisi seng masing-masing temperatur adalah sebesar 1,56\%; 0,27\%; 1,02\% dan 1,80\% (Gambar 6 dan 7)

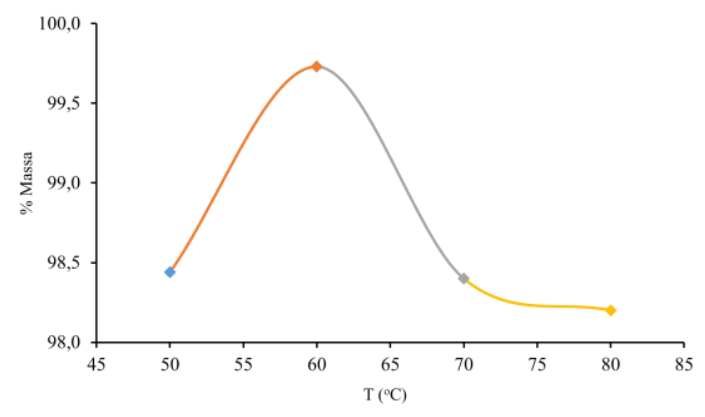

Gambar 6. Persentase massa kobalt (Co) 


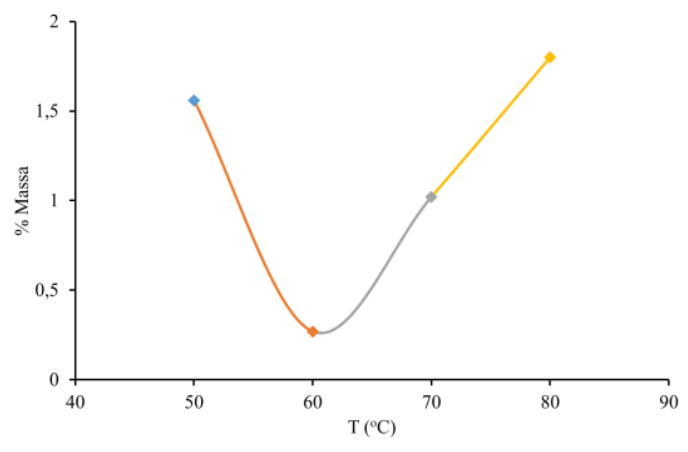

Gambar 7. Persentase massa seng (Zn)

Hasil analisis SEM pada deposit dengan perubahan temperatur ditunjukkan oleh gambar 8-11.

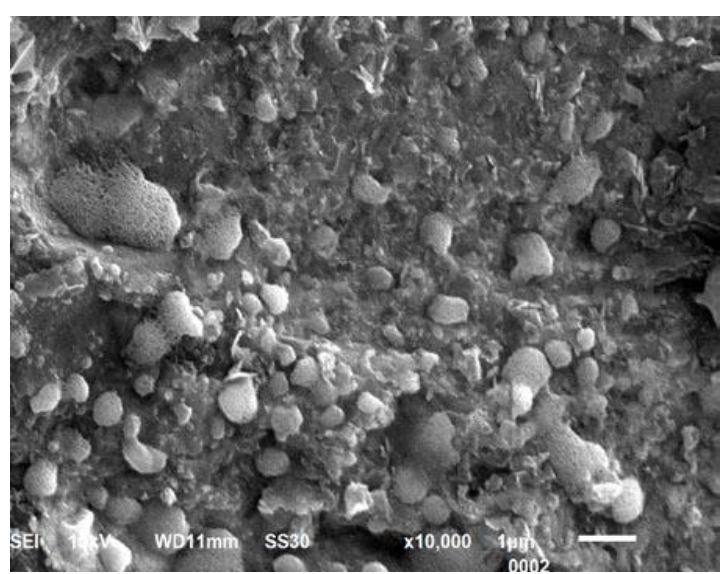

Gambar 8. Morfologi permukaan endapan elektrolisis suhu $50^{\circ} \mathrm{C}$

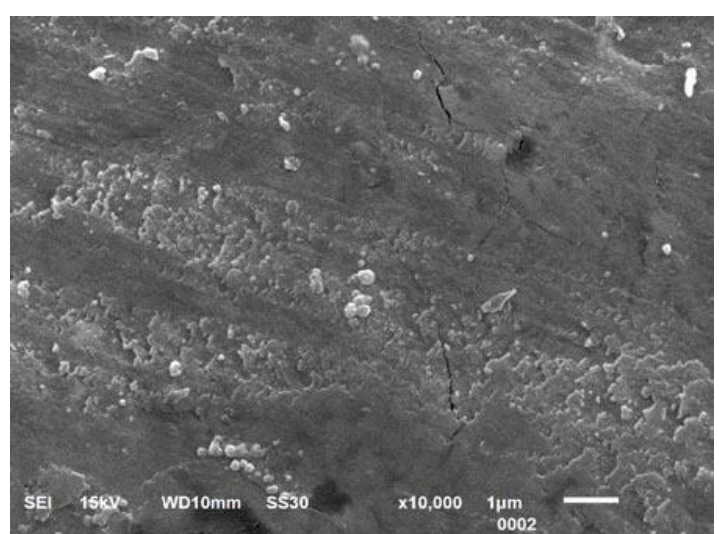

Gambar 9. Morfologi permukaan endapan elektrolisis suhu $60^{\circ} \mathrm{C}$

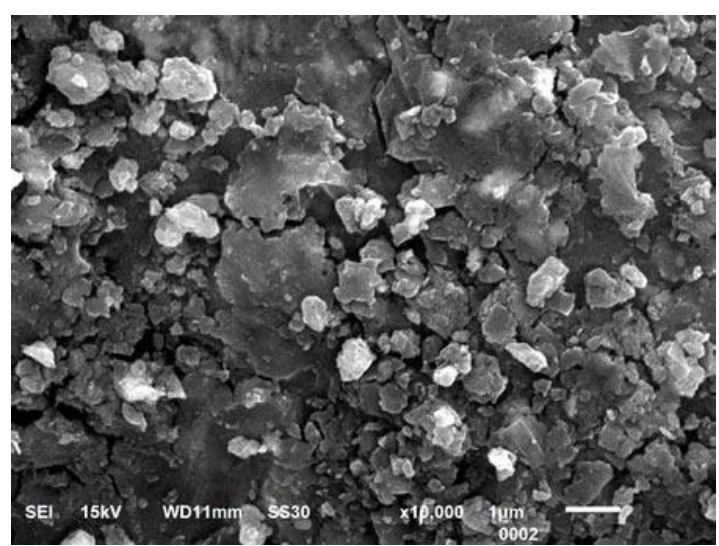

Gambar 10. Morfologi permukaan endapan elektrolisis suhu $70^{\circ} \mathrm{C}$

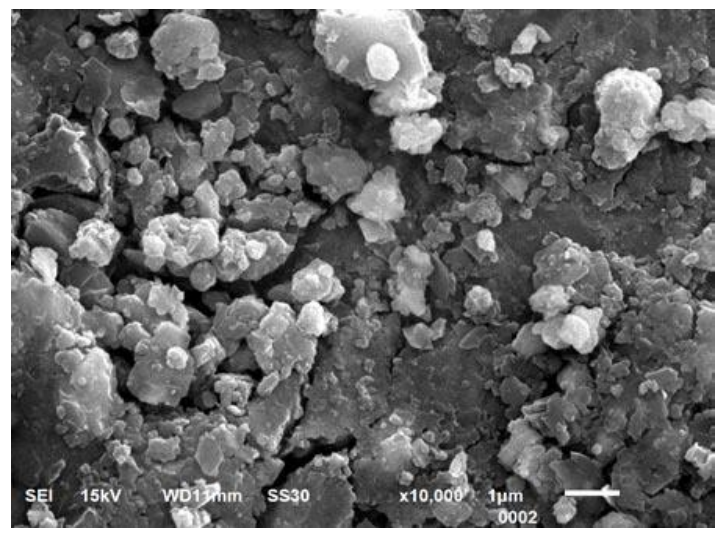

Gambar 11. Morfologi permukaan endapan elektrolisis suhu $80^{\circ} \mathrm{C}$

Hasil analisis SEM yang ditunjukkan pada masingmasing gambar menunjukkan perbedaan kandungan kobalt maupun seng dan mobilitas ion pada tiap-tiap kondisi dalam sistem elektrolisis dengan perubahan temperatur. Perbedaan masing-masing morfologi deposit membuktikan adanya kompetisi pengendapan antara kobalt dengan seng, semakin banyak seng yang terendapkan akan mengurangi kuantitas deposit kobalt yang ditandai dengan berkurangnya kehalusan bulir kristal endapan. Faktor lain yang menyebabkan perbedaan kehalusan morfologi Kristal adalah mobilitas ion dalam proses pengendapan, yaitu pada suhu yang ditingkatkan setelah suhu $60^{\circ} \mathrm{C}$ akan menyebabkan mobiltas semakin tinggi sehingga ion sulit terendapkan di katoda. Hasil morfologi dengan struktur bulir paling halus dan diameter terkecil ditunjukkan oleh endapan hasil elektrolisis suhu $60^{\circ} \mathrm{C}$ artinya pada pengendapan dengan suhu $60^{\circ} \mathrm{C}$ terbentuk kobalt dengan komposisi yang paling banyak dibandingkan dengan seng dengan laju pembentukan gas $\mathrm{H}_{2}$ yang rendah. Fenomena yang berlawanan terlihat pada hasil elektrolisis dengan peningkatan suhu setelah $60^{\circ} \mathrm{C}$, morfologi struktur yang terbentuk menjadi kasar dan semakin kasar dengan semakin meningkatnya suhu karena laju pembentukan gas $\mathrm{H}_{2}$ juga meningkat. Morfologi permukaan endapan paling kasar dengan diameter yang paling besar ditunjukkan oleh hasil endapan suhu $80^{\circ} \mathrm{C}$, yang membuktikan bahwa endapan yang terbetuk saat suhu ditingkatkan hingga $80^{\circ} \mathrm{C}$ menyebabkan peningkatan kodeposisi seng dan gas $\mathrm{H}_{2}$ sehingga mengurangi kehalusan struktur endapan. Berdasarkan hasil penelitian ini menunjukkan bahwa saat adanya pengaruh pengotor Zn pada sistem elektrolisis Co, suhu terbaik yang diperoleh sama dengan sistem elektrolisis tanpa pengotor. Hasil dari masing-masing analisis SEM-EDS menunjukkan bahwa elektrolisis kobalt yang terbaik pada suhu $60^{\circ} \mathrm{C}$ yaitu dengan kemurnian $99,73 \%$ dengan diameter endapan yang terkecil yaitu sebesar $0,26 \mu \mathrm{m}$

\section{Kesimpulan}

Hasil pengendapan Co pada variasi temperatur 50 , 60, 70 dan $80^{\circ} \mathrm{C}$ masing-masing sebesar $98,44 \%$; 
99,73\%; 98,98\% dan 98,20\%, sedangkan persentase $\mathrm{Zn}$ masing-masing sebesar $1,56 \% ; 0,27 \% ; 1,02 \%$ dan $1,80 \%$. Elektrolisis kobalt terbaik berada pada temperatur $60^{\circ} \mathrm{C}$ dengan kemurnian $99,73 \%$ dengan diameter endapan terkecil sebesar 0,26 $\mu \mathrm{m}$

\section{Daftar Pustaka}

[1] Huaiwei Zhang, Yong Li, Jikun Wang, Xin Hong, The influence of nickel ions on the long period electrowinning of zinc from sulfate electrolytes, Hydrometallurgy, 99, 1, (2009) 127-130 http://dx.doi.org/10.1016/j.hydromet.2009.07.009

[2] K Kongolo, CT Mutale, MK Kalenga, Contribution of nickel, zinc and sulphur co-deposistion during cobalt electrowinning, Journal-South African Institute of Mining and Metallurgy, 105, 9, (2005) 599

[3] Buchari, ,, Analisis Instrumental : Tinjauan Umum dan Analisis Elektrometri, FMIPA, ITB bandung, 1990. 